\title{
Sleep characteristics of asthmatics in the first four years of life: a comparative study
}

E Tirosh, A Scher, A Sadeh, M Jaffe, P Lavie

\begin{abstract}
The association between asthma and sleep disturbances was assessed as part of a community survey of sleep patterns in children aged 4-48 months. A questionnaire covering the area of past and present sleep and settling behaviour, as well as health history and demographic data, was administered to 752 mothers of children visiting 14 well baby clinics. Fifty one $(6.8 \%)$ of the children who were diagnosed as having asthma by their paediatricians were compared with the remaining healthy controls (children with perinatal problems, other chronic illnesses, developmental problems, or repeat admissions to hospital were excluded). Thirty nine per cent of the children with asthma and $38 \%$ of the normal controls were identified as regular wakers. The number of interrupted nights each week, settling time, and sleep duration were comparable.

In the children with asthma an uninterrupted night's sleep was acquired later than in the control group. Parental perception of the severity of the sleep problem was similar in the two groups, as were the calming techniques.

It is concluded that this study does not support a significantly increased prevalence of sleep disturbances among young children with asthma compared with their healthy peers.

(Arch Dis Child 1993; 68: 481-483)
\end{abstract}

Sleep disorders in childhood have been attributed to a variety of factors. ${ }^{1}$ Previous studies of children's sleep disorders have devoted relatively little attention to children's physical health as a potential explanatory factor. The respiratory system is of particular interest in relation to sleep. Changes in infants' respiratory patterns were shown in different sleep states ${ }^{2}$ and in sick neonates. ${ }^{3}$ Disorders of the airways such as tonsilladenoidal enlargement, ${ }^{4}$ chronic otitis media, ${ }^{5}$ and allergic disorders ${ }^{6}$ have all been related to sleep disturbances in children. Recurrent attacks of asthma have also been discussed as a potential cause of children's sleep disorders. ${ }^{7-9}$ In addition to the respiratory problem itself, treatment with theophylline may have a stimulating effect on the central nervous system, and thus also result in sleep disturbance. ${ }^{10}$

The psychological profile of the child may also be relevant as an aetiological factor in asthma ${ }^{112}$ and as an inducer of sleep disorders. ${ }^{13-15}$

The purpose of this study was to evaluate sleep characteristics in a group of young children with asthma compared with healthy controls by evaluating the sleep behaviour of the subjects as perceived by their parents.
Subjects and methods

The cohort for this study consisted of a group of 752 children aged 4 months to 4 years attending 14 well baby clinics. The clinics offer service in districts with well defined socioeconomic levels ${ }^{16}$ in the greater Haifa area. Thus all four socioeconomic categories were represented in the cohort, which accurately reflected their distribution in Israeli society. The well baby clinic provides free medical and developmental supervision and preventive health care until the age of 5 years. In the first 2 years of life the attendance in the well baby clinic varies between 85 and $95 \%$ and decreases to $70 \%$ thereafter.

For the purpose of the sleep study, each parent (mother or father) of a child between 4 and 48 months was asked to complete a specially designed questionnaire based on previously published questionnaires ${ }^{17} 18$ which covered the following areas of interest: demographic data, gestational and perinatal history, previous illnesses, and present medical status. Details were also obtained on settling and sleep patterns, and sleep related handling procedures. In addition, the questionnaire included items pertinent to the parents' perceptions of the type and severity of their child's sleep problems. These were scored on a six point scale from 1 'no problem' to 6 'a very severe problem'. The nurses with access to the medical records helped the parents in the completion of the questionnaires whenever necessary. The socioeconomic-status was defined on the basis of parental employment. ${ }^{19}$

The following sleep characteristics were derived from the questionnaires: (a) interrupted nights - the number of interrupted nights each week; (b) number of awakenings - the number of sleep interruptions each night; (c) settling latency (day/night) - the time required to fall asleep; and (d) midsleep latency - the time required to fall asleep once midsleep awakening had occurred. Other characteristics noted were settling and wakening time, sleep duration, age at which all night sleep started, and settling techniques. A child was included in the study group if recurrent wheezing episodes requiring drug treatment were recorded and a diagnosis of asthma was suggested by the doctor treating the child. Children presenting with an active respiratory problem were not included in the study group. No attempt was made to analyse drug regimens or disease severity as a standardised diagnostic/treatment approach was not ascertained.

STATISTICAL ANALYSIS

The $\chi^{2}$ test was used for categorical data, the $t$ test 
Table 1 Sleep characteristics of children with asthma and healthy controls (controlled for age). Values given for children with asthma and controls are mean $(S D)$

\begin{tabular}{|c|c|c|c|c|c|}
\hline & $\begin{array}{l}\text { Children } \\
\text { with asthma } \\
(n=51)\end{array}$ & $\begin{array}{l}\text { Controls } \\
(n=609)\end{array}$ & $\begin{array}{l}\text { Mean }(S E) \\
\text { difference }\end{array}$ & $\begin{array}{l}F \\
\text { Value }\end{array}$ & $\stackrel{p}{\text { Value }}$ \\
\hline $\begin{array}{l}\text { No of waking nights per week } \\
\text { No of awakenings per night } \\
\text { Midsleep latency (min) } \\
\text { Sleep latency (min) } \\
\text { Settling time (hours) } \\
\text { Wake time (hours) } \\
\text { Sleep duration (hours) } \\
\text { Age of attaining quiet night of sleep (months) }\end{array}$ & $\begin{array}{l}4 \cdot 8(2 \cdot 5) \\
1 \cdot 7(0 \cdot 9) \\
7 \cdot 7(6 \cdot 3) \\
17 \cdot 7(14 \cdot 6) \\
20 \cdot 9(0 \cdot 6) \\
6 \cdot 8(1 \cdot 1) \\
10 \cdot 0(1 \cdot 1) \\
10(11 \cdot 8)\end{array}$ & $\begin{array}{l}4 \cdot 7(2 \cdot 5) \\
2 \cdot 0(0 \cdot 9) \\
10 \cdot 4(20) \\
19 \cdot 3(20) \\
20 \cdot 6(0 \cdot 9) \\
6 \cdot 7(0 \cdot 9) \\
9 \cdot 6(1 \cdot 8) \\
5 \cdot 4(6 \cdot 4)\end{array}$ & $\begin{array}{l}0 \cdot 1(2 \cdot 43) \\
0 \cdot 3(0.92) \\
2 \cdot 7(19 \cdot 4) \\
1.6(19 \cdot 1) \\
0 \cdot 3(0 \cdot 91) \\
0 \cdot 1(0.93) \\
0.4(1 \cdot 82) \\
4.6(6.66)\end{array}$ & $\begin{array}{l}0 \cdot 39 \\
0 \cdot 72 \\
0 \cdot 42 \\
0 \cdot 12 \\
0 \cdot 37 \\
0 \cdot 02 \\
0 \cdot 02 \\
3 \cdot 47\end{array}$ & $\begin{array}{l}\text { NS } \\
\text { NS } \\
\text { NS } \\
\text { NS } \\
\text { NS } \\
\text { NS } \\
\text { NS } \\
0.063\end{array}$ \\
\hline
\end{tabular}

for continuous univariate comparisons, and analysis of variance (ANOVA) $2 \times 2$ (sleep characteristics $\times$ age) were used (in spite of no significant age difference between the groups) because of the particular importance of the age factor.

\section{Results}

Seven hundred and thirty eight mothers $(98 \%)$ agreed to participate in the study. Sixty one $(8.3 \%)$ children were excluded from the analysis because of potential confounders such as perinatal and developmental problems. Seventeen additional children were excluded because of a chronic or acute illness requiring admission to hospital for an operation within the $\mathbf{3 6}$ months before the survey, or acute respiratory tract disease.

Fifty one $(6.9 \%)$ children were diagnosed by their doctors as having asthma. Thirty five $(69 \%)$ of these were boys and $16(31 \%)$ were girls. Their mean (SD) age was $23 \cdot 1(13 \cdot 6)$ months. The remaining 609 healthy children constituted the control group. Of these, 310 (51\%) were boys and $299(49 \%)$ girls. This between group gender difference was significant $\left(\chi^{2}=5 \cdot 8 ; p=0 \cdot 01\right)$.

The mean (SD) age of the control group was $19.6(13.6)$ months, which was not signficantly different from the study group $(t=1 \cdot 7 ; p=0 \cdot 08)$.

Twenty (39\%) of the children with asthma were identified by their parents as regular wakers (at least once a week) compared with $38 \%$ of the healthy controls (NS). Nine (45\%) and 109 $(49 \%)$ of the wakers in the asthmatic and control groups respectively were reported to wake every night (NS).

Nocturnal sleep habits of the children with asthma and controls after correction for age differences by analysis of covariance showed no statistical differences (table 1). A trend towards a later age at which an uninterrupted night of sleep was acquired was noted among the children with asthma. The proportion of children who acquired an uninterrupted night of sleep during the second year of life only among the children with asthma (10\%) was significantly higher than the healthy controls $(3 \%)\left(\chi^{2}=6 \cdot 8 ; \mathrm{p}=0.009\right)$.

Table 2 Daytime sleep characteristics of children with asthma and healthy controls (controlled for age). Values given for children with asthma and controls are mean $(S D)$ values

\begin{tabular}{llclll}
\hline & $\begin{array}{l}\text { Children with } \\
\text { asthma } \\
(n=51)\end{array}$ & $\begin{array}{l}\text { Controls } \\
(n=609)\end{array}$ & $\begin{array}{l}\text { Mean }(S E) \\
\text { difference }\end{array}$ & $\begin{array}{l}F \\
\text { Value }\end{array}$ & $\begin{array}{l}p \\
\text { Value }\end{array}$ \\
\hline Times asleep & $1 \cdot 4(0 \cdot 5)$ & $1 \cdot 6(0 \cdot 8)$ & $0 \cdot 22(0 \cdot 7)$ & $0 \cdot 89$ & NS \\
Sleep latency (min) & $9 \cdot 5(5 \cdot 2)$ & $11 \cdot 3(9 \cdot 4)$ & $1 \cdot 8(9 \cdot 1)$ & $1 \cdot 59$ & NS \\
Sleep duration (hours) & $2 \cdot 6(0 \cdot 9)$ & $2 \cdot 9(1 \cdot 5)$ & $0.35(1 \cdot 2)$ & $0 \cdot 00$ & NS \\
\hline
\end{tabular}

Daytime sleep characteristics were comparable between the two groups (table 2).

A comparison of settling techniques showed no differences between the groups. A similar proportion of each group was settled in either their own beds, another place, or in their parents' hands $\left(\chi^{2}=1 \cdot 0 ; p=0 \cdot 6\right)$. The prevalence of additional calming techniques - for example, finger sucking, pacifier, or bottle, was also $\operatorname{similar}\left(\chi^{2}=2 \cdot 1 ; p=0 \cdot 5\right)$.

Parental perception of the number of awakenings or their duration, as the main problem, was similarly distributed in the two groups $(F=1 \cdot 1$; $\mathrm{p}=0 \cdot 29)$. Likewise, perceived severity was similar in the two groups $(F=0.0 ; p=0.98)$. A trend for gender effect was noted in that mothers $(F=3.4 ; p=0.06)$ and fathers $(F=2.79 ; p=0.09)$ identified night interruptions in girls with asthma to be more of a problem than the boys. The opposite was true in the healthy control group.

\section{Discussion}

The purpose of this study was twofold: (a) to evaluate the difference in sleep disturbances and habits between wheezy infants and young children with asthma (not during an active illness) and healthy controls; and (b) to compare parental perception of the problem in the two groups. No significant difference was found between the groups. Under the age of 1 year the diagnosis of asthma is controversial. Although many of these infants will be diagnosed as having asthma in the future, we prefer to define them as 'wheezy infants'. No significant difference was found between the groups in either the prevalence of sleep disturbances or in calming techniques. No differences in parental perception of the problem were observed. It appears, therefore, that despite the possible combination of a recurrent respiratory illness with its attendant psychological stress and drug treatment, this group of children did not present an appreciable increased prevalence of sleep problems. The only reported difference was the later age of acquisition of uninterrupted night sleep. This result, however, could not be causally related to the respiratory problem.

It can be argued that the overall prevalence of sleep disorders in the Israeli community is possibly higher and consequently a specifically attributable risk from asthma will be masked. This is, however, probably not true as the general prevalence of sleep disturbance as perceived by the parents in the healthy group (30\%) was comparable with data from other communities. ${ }^{15} 1720-23$

Of interest is the suggested effect of gender on the parents' perception of the sleep problem among children with asthma compared with controls. Girls were perceived to have more severe sleep disorders. We have no immediate explanation for this observation.

Doubts about the effect of physical illness on the prevalence of sleep problems in childhood have been raised previously by Salzarulo and Chevalier ${ }^{24}$ and in agreement with this observation we were unable to show any association between asthma and sleep problems in the young 
age group studied. One study ${ }^{25}$ suggests an increase in sleep disturbances in adults with asthma, which indicates the effect of possible age and long term factors.

Owing to the lack of diagnostic and treatment standardisation we did not attempt to assess disease severity nor status of drug treatment of the children. The correlation of these two factors with sleep disturbances should be separately assessed in a different design with a larger study group. Further studies should also consider these factors including older children in the cohort.

The authors thank R Abiry for her help in typing this manuscript.

1 Richman N. Update on sleep problems. I Child Psychol Psychiatry 1984; 6: 2-8.

2 Curzi-Dascolova L, Guadelout C, D-Brisac. Respiratory frequencies of sleeping infants during the first months of life: correlations between values and different sleep states. Early Hum Dev 1981; 5: 39-44.

3 Korinthenberg R, Schaten T, Palm D. Sleep state and respiration in newborn infants undergoing phototherapy. Neuropediatrics 1983; 14: 155-9.

4 Guilleminault C. Obstructive sleep apnea syndrome in children. In: Guilleminault C, ed. Sleep and its disorders in children. New York: Raven Press, 1987: 213-24.

5 Ferber R. Sleeplessness, night awakening and night crying in the infant and toddler. Pediatr Rev 1977; 9: 69-82.

6 Simmonds JN, Parraga H. Prevalence of sleep disorders and sleep behavior in children and adolescents. $\mathcal{f}$ Am Acad Child Psychiatry 1982; 21: 383-8.

7 Kales A, Kales JD, Sly R, et al. Sleep patterns of asthmatic children: all-night electropencephalographic studies. children: all-night electr

8 Bixler EO, Kales A, Soldators C, et al. Prevalence of sleep disorders in the Los Angeles metropolitan area. Am $\mathcal{F}$ Psychiatry 1976; 136: 1257-62.
9 Smith TF, Hudgel DW. Arterial oxygen desaturation during sleep in children with asthma and its relation to airway obstruction and ventilatory drive. Pediatrics 1980; 66: 74651 .

10 Hendeles L, Weinberger M. Theophyllin: a state-of-the-art. Review. Pharmacotherapy 1983; 3: 2-44.

11 Denhoff E, Feldman SA. Behavior perspectives in children with chronic disabilities: a pediatric viewpoint. Developmental Behaviour in Pediatrics 1987; 2: 97-104.

12 Steinhauser HC, Schindler HP, Stephan H. Correlation of psychopathology in sick children: an empirical model. $\mathcal{f} \mathrm{Am}$ Acad Child Psychiatry 1983; 22: 559-64.

13 Coates TJ, Thorenson CE. Treating sleep disorders. In: Turner SM, Calhoun KS, Adams HE, eds. Handbook of clinical behavior therapy. New York: Wiley, 1981: 240-89.

14 Kataria S, Swanson MS, Trevathan GS. Persistance of sleep disturbances in preschool children. Behavioural Pediatrics disturbances in p

15 Richman N. Surveys of sleep disorders in children in a general population. In: Guilleminault C, ed. Sleep and its disorders in children. New York: Raven Press, 1988: 115-27.

16 The Statistical Abstract of Israel V-39. Jerusalem: Central Bureau of Statistics. 1988.

17 Richman N. A community survey of characteristics of one-to two-years old with sleep disruptions. $\mathcal{f}$ Am Acad Child Psychiatry 1981; 20: 281-91.

18 Van Tassell EB. The relative influence of child and environmental characteristics of sleep disturbances in the first and second years of life. Developmental Behaviour in Pediatrics 1986; 6: 81-5.

19 Office of Population Census and Surveys. Classification of occupations 1970. London: HMSO, 1971.

20 Moore T, Ucko LE. Night waking in early infancy. Part I. Arch Dis Child 1957; 32: 333-42.

21 Bernal JF. Night waking in infants during the first 14 months. Dev Med Child Neurol 1973; 15: 760.

22 Beltramini AV, Hertzig ME. Sleep and bedtime behavior in preschool-aged children. Pediatriia 1983; 71: 153-8.

23 Jenkins J, Owen C, Bar M, Hart H. Behavior problems in preschool children. F Child Psychiatry 1984; 25: 75-89.

24 Salzarulo $P$, Chevalier A. Sleep problems in children and their relationships with early disturbances of the waking-sleeping relationships with early disturb
rhythms. Sleep 1983; 6: 47-51.

25 Jarson C, Gislaron T, Rowan G, Hetta J, Roos BF. Sleep

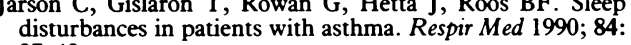
$37-42$. 